\title{
Biocomposites based on collagen and keratin with properties for agriculture and industrie applications
}

\author{
Mihaela-Doina Niculescu ${ }^{1 *}$, Doru-Gabriel Epure², Magdalena Lasoń - Rydel³, \\ Carmen Gaidau $^{1}$, Mihai Gidea ${ }^{4}$ and Cristina Enascuta ${ }^{5}$
}

\begin{abstract}
In the present research biocomposites based on extracts of collagen and keratin recovered from the leather industry by-products were made and the specific properties for applications in agriculture and industry were studied. To this aim, collagen and keratin have been extracted from bovine leather and sheep wool by-products and have been added and crosslinked with recognized compounds for reduced environmental impact (glycerol, vegetable tanning extract, essential oils with fungicidal properties and insecticides). The biocomposite properties were evaluated on the basis of complex analytical investigations on chemical structure, texture, contact angle, mechanical resistance, water vapor permeability and water absorption, biodegradation, germination and plant biomass growth. The biocomposites have demonstrated pelliculogenic properties and nitrogen controlled release to stimulate germination and nutrition of rape seedlings, which promotes them for agricultural applications, but also other surface properties have been identified, for industrial applications, for example in leather finishing for special destinations. Addition of odorous principles with controlled release recommends this type of biocomposites for environmentally friendly products, maintenance of cleaning, etc.
\end{abstract}

Keywords: Biocomposite, crosslinked, surface properties, controlled nitrogen release

'Leather Research Department, INCDTPLeather and Footwear Research Institute Division, Bucharest, Romania

2Probstdorfer Saatzucht Romania SRL, Bucharest, Romania

${ }^{3}$ Environment Laboratory, RESEARCH NETWORK ŁUKASIEWICZ - Institute of Leather Industry, Lodz, Poland

${ }^{4}$ Soil Sciences Department of Agriculture Faculty, University of Agronomic Science and Veterinary Medicine, Bucharest, Romania

${ }^{5}$ Bioresurse Department, Nationa Institute for Research and Development in Chemistry and Petrochemistry ICECHIM, Bucharest, Romania

*Corresponding author: M-D. Niculescu E-mail: mihaelaniculescu59@yahoo.com

DOI: 10.2478/ebtj-2019-0019

(C) 2019 Authors. This work was licensed under the Creative Commons AttributionNonCommercial-NoDerivs 4.0 License.

\section{Introduction}

For the most part, scientific studies dedicated to biocomposites based on collagen and keratin have been oriented towards the medical field, especially for regeneration, vascular and cardiac reconstruction, cosmetic treatments (1). Studies on collagen mixtures with synthetic polymers have been aimed both at making materials for medical use $(2,3)$ and for industrial applications such as biodegradable films, finishing binders, adhesives for the wood industry (4). For example, studies on collagen and keratin extracts used in the formulation of adhesives for the wood industry have revealed antioxidant activity and a significant reduction in formaldehyde emissions from urea-formaldehyde adhesives $(5$, 6). In recent years, most studies of collagen and keratin extracts have been directed to harnessing the biostimulation and nutrition potential of plants (7-9), making anti-felting treatments for wool (10), synthesis of polymeric materials functionalized with $\mathrm{Fe}_{3} \mathrm{O}_{4}$ nanoparticles to remove Bisphenol A from water (11). Other studies have promoted the possibility of obtaining collagen extracts with the potential to promote flocculation of sludge, kaolin or even the preparation of a modified collagen-based flocculant for the treatment of waste water. It is worth noting that the molecular weight of the collagen extracts may to influence the flocculant potential, which is disadvantaged under the conditions of low molecular weights (12-14). Recent studies have shown increasing flocculation efficiency from about $70 \%$ to $95 \%$ by associating acrylamide with collagen hydrolysates with a 15 $\mathrm{kDa}$ molecular weight intermediated by electron beam irradiation (15). If for medical applications collagen and keratin extracts are obtained from primary sources with very rig- 
orous traceability, for the industrial domain secondary resources can also be accessed. Secondary protein resources generated by the leather processing industry and the agro-food industry are an accessible and low cost but less exploited raw material. In the present research, proteins, collagen and keratin were extracted from the leather processing by-products which were used to obtain biocomposites with properties specific to application in the agricultural field, with effects on stimulating germination, nutrition and plant protection in various stages of vegetation and that can be exploited in other applications, in accordance with the current trends of circular economy development.

\section{Materials and Methods}

\section{Materials}

The bovine leather by-products was obtained from SC Pielorex SA, Romania and wool by-products from the Leather and Footwear Research Institute Division, Romania, for collagen and keratin extraction, as gelatin with average molecular weight over $30 \mathrm{kDa}$ and keratin hydrolysate with average molecular weight below $15 \mathrm{kDa}$.

Glacial acetic acid p.a (SC Cristal R Chim SRL) for $\mathrm{pH}$ corrections.

Ammonia solution $25 \%$ p.a, anhydrous sodium carbonate p.a from Chimreactiv SRL and ethoxylated alkyl non-ionic detergent from Borron SE for wool degreasing.

Hydrated calcium oxide p.a from SC Cristal R Chim SRL for wool hydrolysis.

Vegetable tara tannin from Leather Quimica SLU was used as powder with volatile matter content 8.6 and tannin content $39 \%$ to obtain tannin extract.

Glycerol were products of SC Chimopar SA Romania.

Essential oils for pharmaceuticals from Solaris Plant SRL Romania.

Rape seed of varieties HARRY C, JEREMY C, PEDRO F1 from Probstdorfer Saatzucht Romania SRL.

\section{Methods}

Bovine skin gelatins were obtained by thermal hydrolysis of the semi-processed leather by-products in the temperature range of $70-90^{\circ} \mathrm{C}$, at $\mathrm{pH} 5.5-6.0$ (GBF, with $6.67 \%$ protein) and concentration in vacuum (GBPC, with $18.25 \%$ protein);
The Tara extract (with 5\% dry substance, 4\% tanning substances) was obtained by hydrolyzing the Tara powder in water at a temperature of $60-80^{\circ} \mathrm{C}$ for a period of 1-2 hours, centrifugation and vacuum filtration on cellulosic membranes (16).

The keratin extract (with 5\% dry substance, $65 \%$ protein) was obtained by alkaline hydrolysis of sheep wool waste at $80^{\circ} \mathrm{C}$ for 24-28 hours, centrifugation and vacuum filtration (17).

Biocomposites based on collagen and keratin were made by combining extracts of collagen and keratin with glycerol as a plasticizer, crosslinked with Tara vegetable extract and additivated with essential oils with insecticidal-fungicidal effects (cinnamon oil, thyme oil) demonstrated in previous research (18). The combinations made are described in Table 1.

Determination of the consistency of biocomposites in the form of gels and film penetration test were carried out using a TEX'AN texture analyser. Gel consistency is expressed by maximum force (Fmax. in grams) required by a cylindrical probe (Bloom cylinder) for the compression of gel placed in a standard glass recipient, with a diameter of $59 \mathrm{~mm}(+/-1 \mathrm{~mm})$ and height of $85 \mathrm{~mm}$, under standard conditions: sensor with a diameter of 0,5 inch, penetration rate $0,5 \mathrm{~mm} / \mathrm{s}$, penetration distance $4 \mathrm{~mm}$.

The penetration test of the films cast from the respective compositions allows determination of the breaking point using a standard $3 \mathrm{~mm}$ cylindrical probe.

Contact angle were determined by VCA Optima XE.

Vapour permeability and water absorption were analyzed according to ICPI in house methods;

The water biodegradation test of collagen-keratin-based films was performed by immersing the pellets in distilled water at a $1 / 40$ weight/volume ratio, incubating at $20^{\circ} \mathrm{C}$ and periodically withdrawing liquid samples that were analyzed for quantification of total nitrogen yielded by the film.

SR ISO 5397-96, Finished leathers. Total nitrogen determination.

\section{Results}

The consistency of the biocomposite formed by cross-linking and additivation (GBCA) was studied in comparison with concentrated gelatin (GBPC) used as a base and with a standardized gelatin (GBF). The results of the analysis are shown in Fig.1.

This type of behavior is also confirmed by the penetration

Table 1. Description of biocomposites based on collagen and keratin

\begin{tabular}{|c|c|c|c|c|c|c|c|}
\hline \multirow{2}{*}{ No. } & \multirow{2}{*}{ Biocomposites } & \multirow{2}{*}{$\begin{array}{l}\text { Description of } \\
\text { biocomposites }\end{array}$} & \multirow{2}{*}{ Gelatin, \% } & \multicolumn{4}{|c|}{ Crosslinker / additive, \% } \\
\hline & & & & Tara extract & Glycerol & $\begin{array}{c}\text { Keratin } \\
\text { hydrolysate }\end{array}$ & $\begin{array}{c}\text { 1:1 mix of } \\
\text { essential oils }\end{array}$ \\
\hline 1 & GBT & Crosslinked GBF gelatin & 88.0 & 4.0 & 8.0 & - & - \\
\hline 2 & GBKT & $\begin{array}{l}\text { Crosslinked-additivated } \\
\text { GBF gelatin }\end{array}$ & 80.0 & 4.0 & 8.0 & 8.0 & - \\
\hline 3 & GBCA & $\begin{array}{l}\text { Crosslinked-additivated } \\
\text { BPC gelatin }\end{array}$ & 60.5 & 9.1 & 12.1 & 18.2 & 0.1 \\
\hline
\end{tabular}



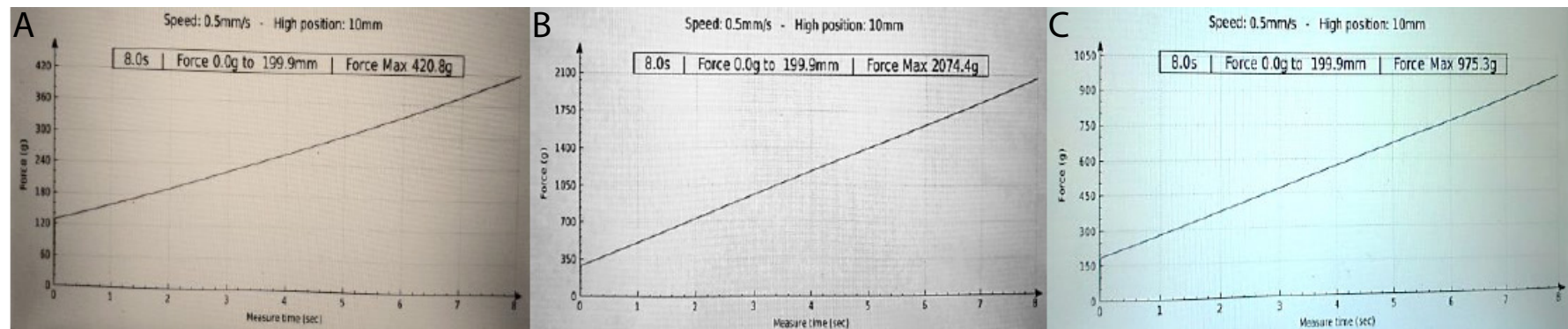

Figure 1. Determination of gel strength: A) GBF; B) GBPC; C) GBCA.
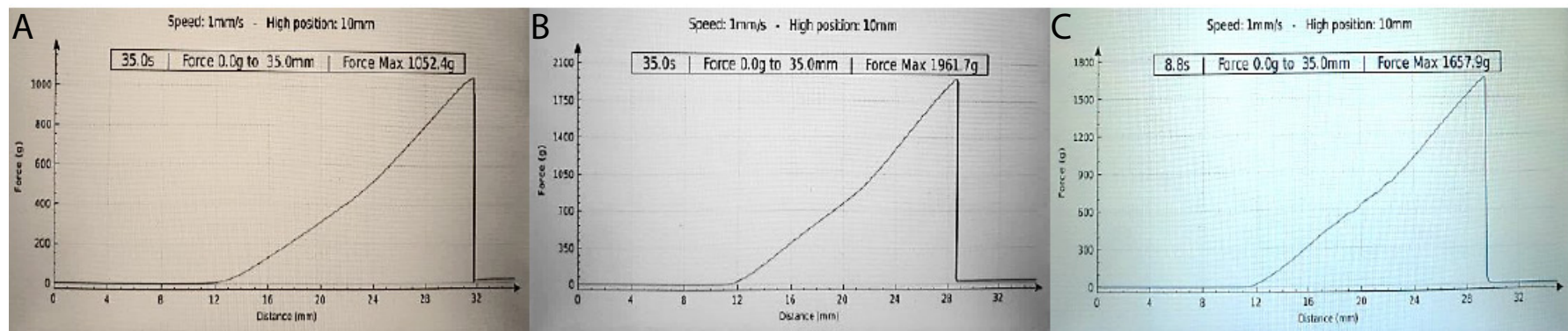

Figure 2. Determination of film resistance: A) GBF; B) GBPC; C) GBCA.

test of the films cast from the respective compositions, Fig. 2, through which the breaking point is determined.

Analytical data indicates that by concentrating gelatin, the maximum force increases steadily nearly 5 times (from 420.8 $\mathrm{g}$ to $2074.4 \mathrm{~g}$ ), but decreases by crosslinking and additivation (from 2074.4 g to $975.3 \mathrm{~g}$ ).

Two types of films, one consisting of collagen, P1, made from GBT biocomposite, and one made of collagen and kera- tin, P2, made from GBKT biocomposite, were studied.

The determination of the water contact angles in dynamic conditions, both on the contact surface with air during film drying (f1) and on the contacting surface with the casting support (f2), is shown in Table 2.

Comparative results are illustrated in Fig. 3.

The results show that after about 5 minutes of contact with water, the angles decrease significantly to the hydrophilic range.

Table 2. The dynamic of contact angle

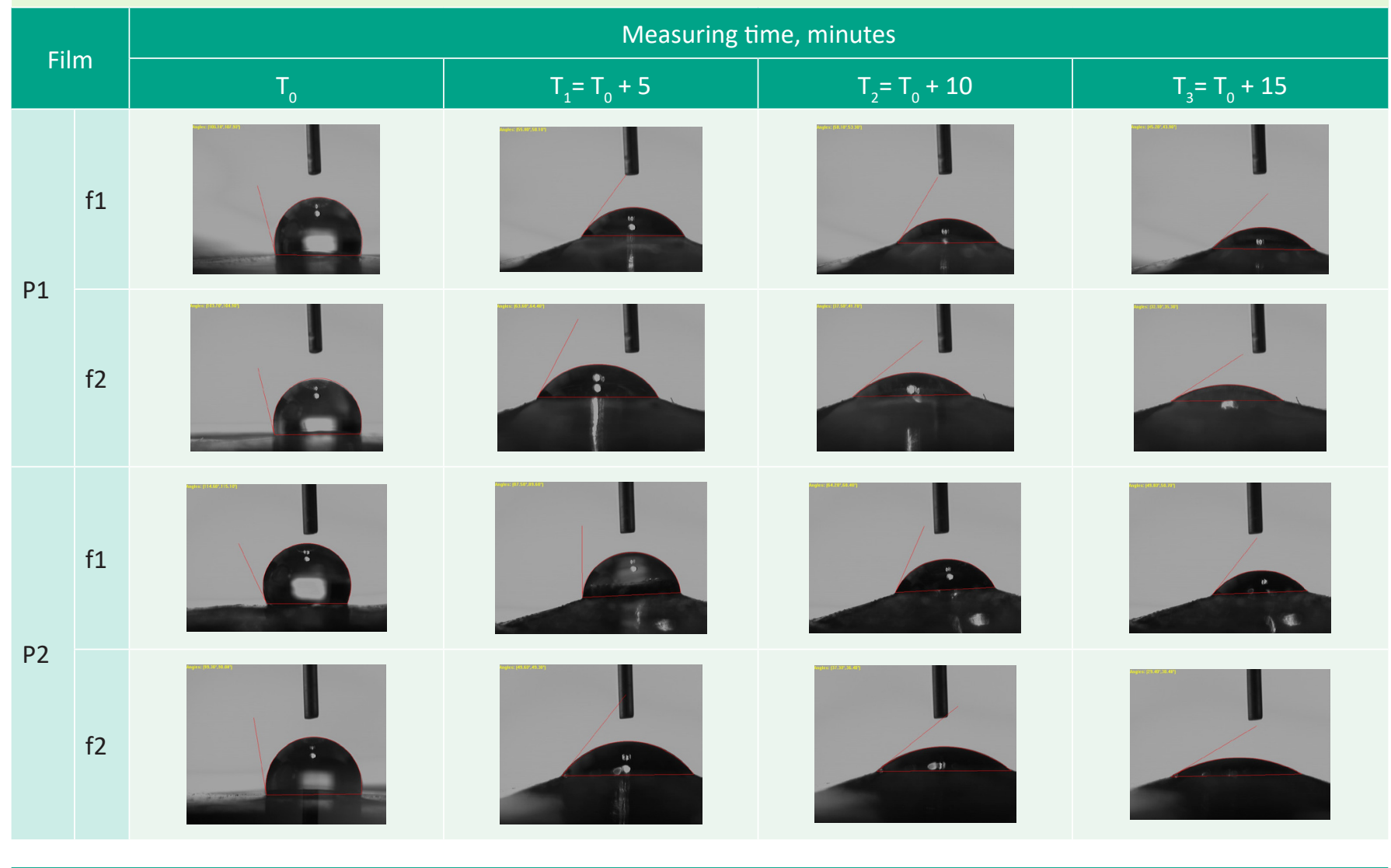




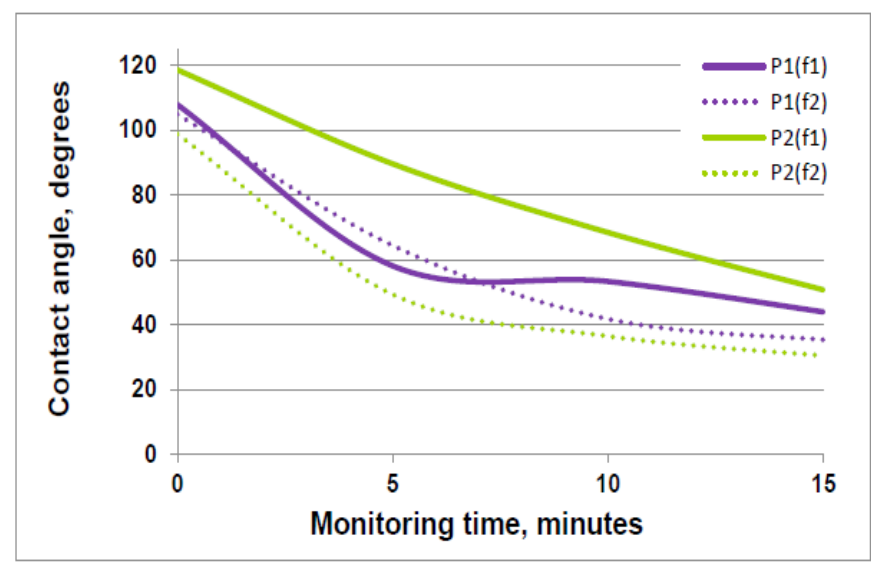

Figure 3. The evolution of the contact angle of collagen films when interacting with water.

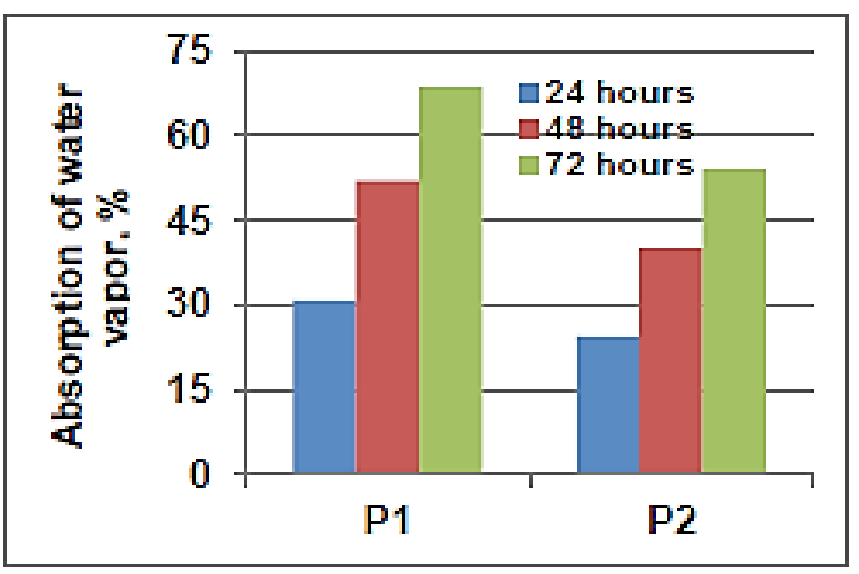

Figure 5. Water vapor absorption.

Table 3. Nitrogen release rate through film biodegradation

\begin{tabular}{|c|c|c|}
\hline \multirow{2}{*}{$\begin{array}{c}\text { Number of } \\
\text { monitoring days }\end{array}$} & \% nitrogen solubilised from the film \\
\cline { 2 - 3 } & P1 & P2 \\
\hline 0.4 & 4.14 & 4.45 \\
\hline 2 & 7.73 & 8.48 \\
\hline 3 & 9.10 & 9.78 \\
\hline 6 & 16.09 & 11.01 \\
\hline 10 & 17.03 & 16.67 \\
\hline 12 & 19.50 & 18.25 \\
\hline 14 & 21.51 & 17.60 \\
\hline 20 & 29.58 & 22.47 \\
\hline 25 & 66.22 & 26.19 \\
\hline 32 & 71.91 & 32.75 \\
\hline
\end{tabular}

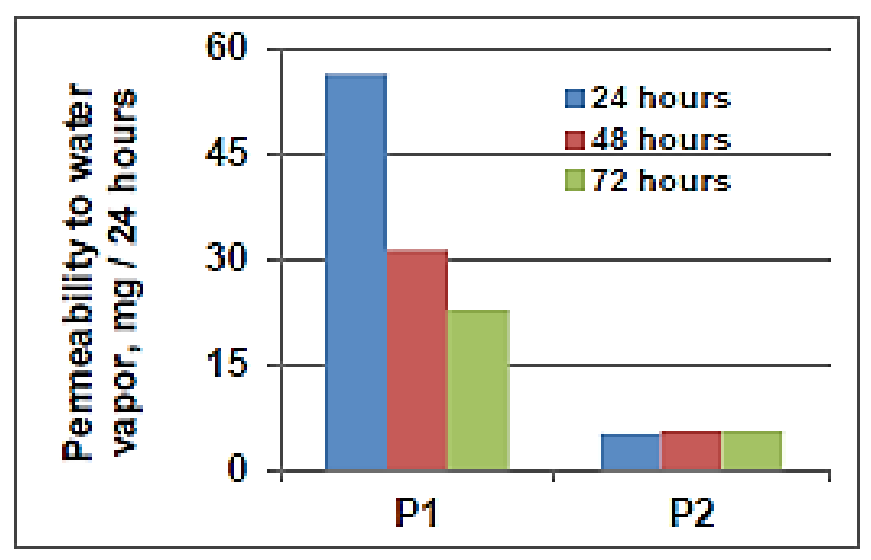

Figure 4. Permeability to water vapors.

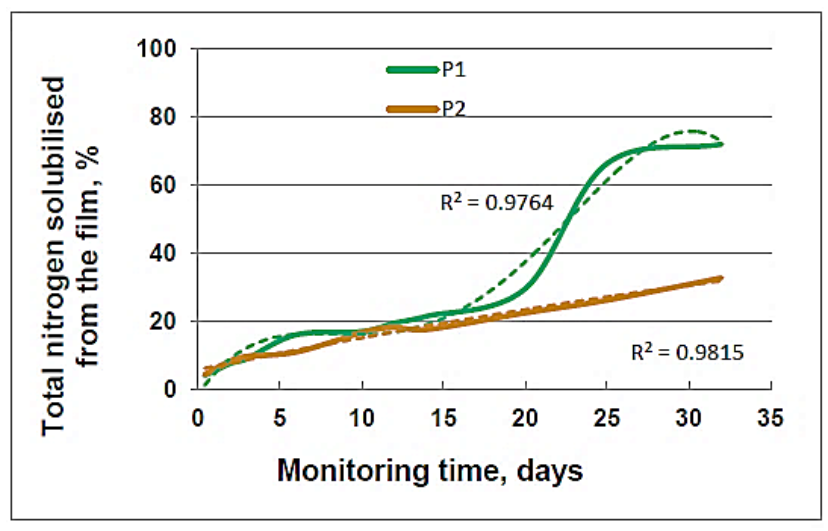

Figure 6. Total nitrogen release rate from films.

Other important characteristics for seed treatment applications are water vapor permeability and water absorption of films, being closely related to the physiological processes that develop during seed germination and sprouting. Determinations of these characteristics for the two films are shown in Figs. 4 and 5 .

As the treatment of rapeseeds with collagen extracts involves both the immediate availability of amino acids to stimulate germination and the gradual availability of nitrogen for plant and seedling nutrition, the rate of nitrogen release from films consisting of collagen and keratin -based biocomposites P1 and P2 was studied using the water biodegradation test.

The statistical data collected from the biodegradation test described is shown in Table 3.

The test result is shown in Fig. 6.

From the data obtained, it was found that the P1 film, which does not contain keratin, had a marked degradation, $71.91 \%$ in 32 days, while $\mathrm{P} 2$ film, which contains keratin, degrades significantly slower, $32.75 \%$ in 32 days. 


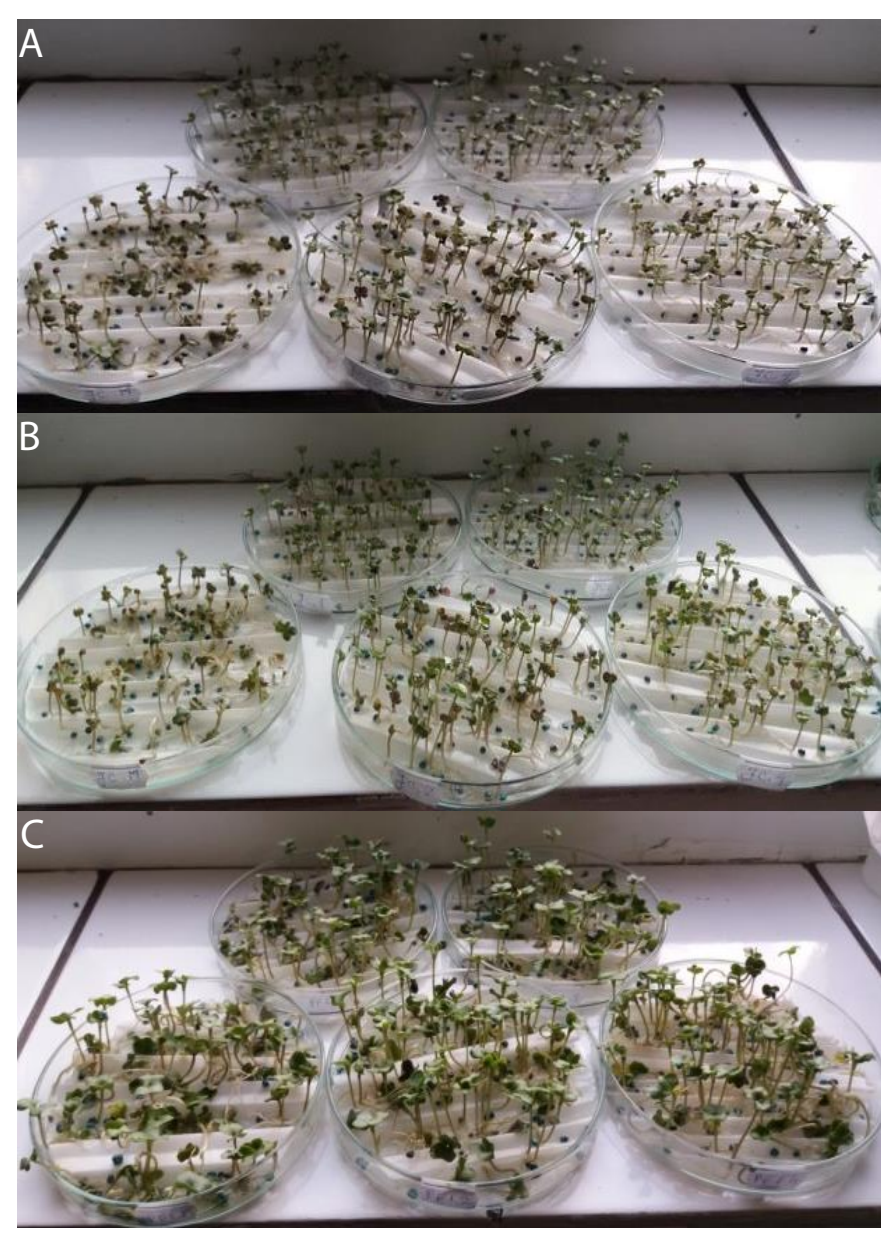

Figure 7. Rape seedlings after seven days from the start of germination test: A) HARRY C variety; B) JEREMY C variety; C) PEDRO F1 variety.

Germination tests were carried out for three types of rapeseed (HARRY C, JEREMY C, PEDRO F1) covered with film made from the GBCA biocomposite, and data were recorded after 4 days to determine germination energy and after 7 days to establish germination, the increase in thickness of seedlings and the increase of biomass, compared to controls treated with water and collagen extracts (gelatin, hydrolysate and gelatin combined with hydrolysate), Fig. 7 and Fig. 8.

From the data obtained, it was found that GBCA biocomposite led to germination of over $90 \%$ and significant increases in biomass to $38.70 \%$ compared to the water-treated control samples.

\section{Discussions}

The most important feature of collagen and keratin based biocomposites for agricultural applications consists in its pelliculogenetic properties, whether they are plant or soil fertilizers, support bands for very small seeds, biodegradable packaging, etc. From this point of view, this research was aimed at making biocomposites capable of forming pellets on the surface of rapeseeds, to improve germination, rape nutrition in the sprouting period, but also protection against insects and fungi. In addition to the organic nitrogen intake from collagen and

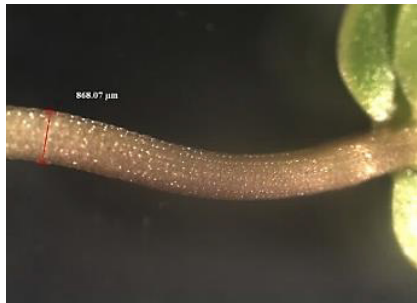

(a)

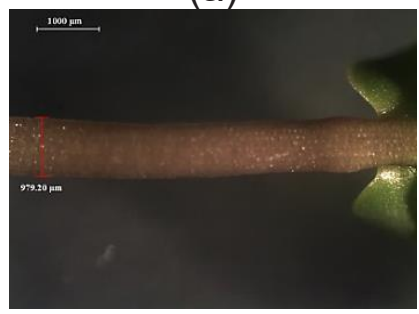

(c)

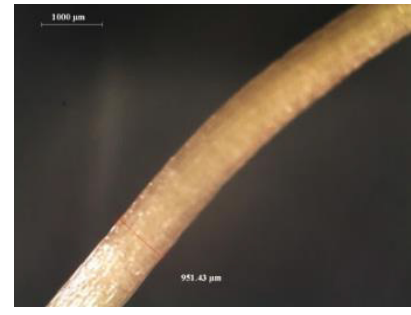

(b)

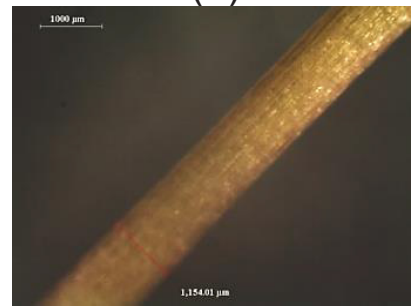

(d)
Figure 8. Evolution of control seedlings treated with water (M) and treated with GBCA biocomposite resulting from PEDRO F1 (PF) rapeseeds: (a) M after four days; (b) M after seven days; (c) PF after four days; (d) PF after seven days.

keratin, the new biocomposites additionally bring a sulfur intake from keratin, and essential oils of cinnamon and thyme contribute with insecticide-fungicidal effects, as demonstrated in previous research (18).

Increase the gelatin strength, Figure 1, by concentration and lower it by crosslinking and additivation is natural, because by concentration there are peptide combinations with the elimination of water, and the additivation of low molecular weight hydrolysate causes the insertion of small particles, even oligopeptides and free amino acids, by physical bonds, inducing the formation of weaker areas. In the penetration test of the films cast from the respective compositions, Figure 2, a force is applied to the sample to deform it up to the point of breaking. This is a common method also used to measure weaknesses in a film, simulating the circumstances in which a material may break during packaging and transport.

These results confirm the need to concentrate the gelatin over the standard concentration threshold to give it sufficiently high resistance to mitigate the significant decrease caused by subsequent additivation with protein hydrolysates and other additives.

An important role in the physico-chemical interactions between the films and the environment with which they interact is that of the surface properties, defined by the surface energy parameters and water adhesion to the film. The energy characteristics of films were determined by the contact angle method, which is a direct measure of the interactions that take place between the surface of the film and the drop of distilled water. In previously published works $(19,20)$, water contact angles of collagen-based films have been shown, only for surfaces contact with air during the drying of the film on grain seeds prepared for sowing. In this paper, other potential applications of collagen-based and keratin-based films were considered, where 
information on both sides of a film detached from a casting support would be useful, Table 2 and Fig. 3. It is pointed out that the casting support guided the arrangement of the polypeptides so that both films exhibit the same tendency on the contact surface with the casting support, both initially having a contact angle $>90^{\circ}$ but exhibiting different behaviors on the surfaces which were in contact with the air during drying, although both initial contact angles were $>90^{\circ}$. However, for both types of films and on both sides the angles decrease significantly to the hydrophilic range after about 5 minutes of contact with water.

In terms of water vapor permeability and water absorption of films shown in Figs. 4 and 5 the P1 film exhibits sufficiently high permeability and absorption to allow the seed to breathe during germination and the P2 film has a low permeability but has a sufficiently high absorption.

The results of biodegradation test of P1 and P2 films, Table 3 and Fig. 6, shown a polynomial trend of order 4 for the degradation of P1 film, while the degradation tendency of P2 film is polynomial of the order 2 . The different appearance and orders are influenced by the much larger fluctuation of the data for the P1 film compared to P2. In both cases, the average square deviation value is close to 1 (0.9764 and 0.9815$)$, which is a good correlation of the trends with the data. The behavior of P2 film, containing keratin extract, creates the premises for the development of retarded degradation products, which will slowly release the proteins for fertilization in different vegetation phases of plants.

The responses of germination tests carried out for three types of rapeseed treated with water and collagen extracts, Fig. 7 and Fig. 8, are significantly different due to the different types of seeds, but the most important signals are given by the type of seed treatment. The increase in biomass can be determined either by the more pronounced development of the roots (in the case of JEREMY C variety) or by the more pronounced development of the plants (in the case of PEDRO F1 variety), which showed an increase in stem thickness of over $17 \%$ between the fourth and seventh day from the start of the germination experiment (Fig. 8), almost double compared to the growth of stems from the water-treated control seeds.

At present, the published studies $(21,22)$ refer to the extraction of collagen from fish skin for application in the rape production in the final stage of vegetation, to cover the silicves and to prevent the dehiscence. In these reference works, only the collagen hydrolysates from fish skin has been tested also in rapeseed germination. The present papers refer to application of collagen-based products from bovine skin and wool keratin to stimulate germination of rape seeds and plants nutrition in the start of vegetation.

Correlation of this information with other specific data (e.g. with soil characteristics) can lead to the initiation of high-performance rapeseed cultures, reducing the contribution of synthetic agrochemicals by compensating with collagen and keratin based compositions recovered from secondary resources. In agriculture, the properties of biocomposites can be exploited both in the fertilization of crops and in soil fertilization, conditioning and protection.

These properties of biocomposites containing collagen and keratin are also specific to other applications in various industrial fields, and can lead to the creation of products to finish special purpose leather, environmentally friendly cleaning, maintenance and freshening products, biodegradable packaging.

\section{Conclusions}

Biocomposites based on extracts of collagen and keratin recovered from the leather industry by-products have the ability to form films with controlled biodegradability.

Treating rape seeds with biocomposites based on extracts of collagen and keratin leads to total biomass increase up to $38 \%$.

Biocomposites based on extracts of collagen and keratin recovered from the leather industry by-products presents properties that can be exploited, such as crop fertilization and crop protection products, soil quality improvement products or as sowing and planting media, to increase agricultural output, but also for industrial applications with a higher degree of environmental protection.

\section{Acknowledgement}

This work was supported by the grants of Romanian National Authority for Scientific Research and Innovation, CCCDI - UEFISCDI, project number: PN-III-P3-3.5-EUK-2016-0029 / COLL-RAPE (contract no. 93/2017); PN 19.17.01.02 (contract no. 19N/2019) and the article is funded by the Ministry of Research and Innovation within Program 1 - Development of the national RD system, Subprogram 1.2 - Institutional Performance - RDI excellence funding projects, Contract no. 6 PFE/16.10.2018.

\section{Conflict of interest statement}

The authors declare that they have no conflict of interest.

\section{Ethical compliance}

This article does not contain any studies involving human participants or animals performed by any of the authors.

\section{References}

1. Rodriguez MIA, Barroso LGR, Sanchez ML. Collagen: A review on its sources and potential cosmetic applications. J Cosmet Dermatol 2018; 17(1): 20-26.

2. Delgado LM, Shologu N, Fuller K, Zeugolis DI. Acetic acid and pepsin result in high yield, high purity and low macrophage response collagen for biomedical applications. Biomed Mater 2017; 12(6): article no. 065009.

3. Fu W, Liu ZL, and al. Electrospun gelatin/PCL and collagen/PLCL scaffolds for vascular tissue engineering. Int J Nanomed 2014; 9: 2335-2344.

4. Sedliačik J, Jurkovič P, Niculescu M. Application of Collagen Colloid from Chrome Shavings for Innovative Polycondensation Adhesives. In: Fourth Scientific and Technical Conference IUFRO Sofia, Bulgaria 2011.

5. Matyasovsky J, Jurkovic P, Skultety J, et al. Collagen and keratin as environmentally friendly natural polymers for modification of wood adhesives. In: Proceedings of 2nd International Scientific Conference"Wood-Science-Economy" Poznan, Poland 2017; 1: 73. 
6. Matyasovsky J, Sedliacik J, Novak I, et al., Antioxidant Activity of Keratin Hydrolysates Studied by DSC. In: 114th Annual Convention of The American Leather Chemists Association, Itasca, IL, U.S.A. 2018.

7. Gaidau CC, Niculescu MD, Epure DG, Stepan E, Gidea M. Bioproducts based on collagen and keratin for seeds and plant treatment. J Biotechnol 2017; 256 Supplement: S110.

8. Niculescu MD, Gaidau C, Epure DG, Gidea M. Experimental Observations About Improving the Properties of Collagen Extracts for Applications in Agriculture. Rev Chim-Bucharest 2018; 69(2): 379385.

9. Berechet MD, Niculescu M, Gaidau C, Ignat M, Epure DG. Alkaline-Enzymatic Hydrolyses of Wool Waste for Different Applications. Rev Chim-Bucharest 2018; 69(7): 1649-1654.

10. Du Z, Ji B, Yan K. Recycling keratin polypeptides for anti-felting treatment of wool based on L-cysteine pretreatment. J Clean Prod 2018; 183: 810-817.

11. Hassanzadeh M, Ghaemy M. Preparation of bio-based keratin-derived magnetic molecularly imprinted polymer nanoparticles for the facile and selective separation of bisphenol A from water. J Sep Sci 2018; 41(10): 2296-2304.

12. Piazza GJ, Garcia RA. Proteins and peptides as renewable flocculants. Bioresource Technol 2010; 101: 5759-5766.

13. Piazza GJ, Garcia RA. Proteolysis of meat and bone meal to increase utilization. Anim Prod Sci 2013; 54(2): 200-206.

14. Wang XC, Zhang S, Zhou L, Ren LF. Preparation and characterization of a cationic flocculant based on modified collagen. Journal of Functional Materials 2011; 42(12): 2221-2224.

15. Craciun G, Manaila E, Niculescu M, Ighigeanu D. Obtaining a new type of polyelectrolyte based on acrylamide and hydrolyzed collagen by electron beam irradiation. Polymer Bulletin, 2017; 74(4): 1299-1326.
16. Gaidau C, Simion D, Niculescu MD, Paun G, Popescu M, Bacardit A, Casas C. Tara Tannin Extract Improvement. Part I: Extraction and Concentration Through Membranary Filtration Techniques. Rev. Chim.-Bucharest 2014; 65(8): 929-933.

17. Niculescu MD, Berechet MD, Gaidau C, Ignat M, Radu M. Study on obtaining keratin extracts from leather industry by-products. In: Proceedings of ICAMS 2016 - 6th International Conference on Advanced Materials and Systems, Bucharest, Romania 2016: 477482.

18. Stepan E, Velea S, Epure DG, Gaidau CC, Niculescu MD, Gidea M. Compositions containing microencapsulated essential oils and plant biostimulants, for sustainable agriculture. J Biotechnol 2017; 256 Supplement: S110.

19. Niculescu M, Gaidau C, Chen W, Gavrila R, Ignat M, Epure DG. Studies for Production and Characterization of Collagen Layers for Agricultural Applications. IJASEAT 2017; 5(4) Spl. Iss-2: 10-14.

20. Gaidau C, Epure DG, Niculescu M, Stepan E, Radu E, Gidea M. Application of Collagen Hydrolysate in Cereal Seed Treatment, In: e-Proceedings of $33^{\text {rd }}$ International Association of Leather Trades Chemists Congress (IULTCS 2015), Novo Hamburgo, Brazil 2015; article no. 072: 1-7.

21. Gidea M, Stepan E, Enascuta EC, Gaidau C, Niculescu M, Epure DG, Cioineag C, Sandulescu EB, Epure LI. Researches on the biostimulating and antidehiscent effect of products based on fish collagen crosslinked to rape crop, J Biotechnol 2017; 256 Supplement: S100.

22. Gaidau C, Niculescu M, Epure DG, Becheritu M, Gidea M, Stepan E. Collagen based bio-functional products for plant treatment, Proceedings of International Conference Agriculture and Food for XXI, Sibiu, Romania, 2017: 52-59. 